\title{
POST-CHORNOBYL REMOTE RADIATION EFFECTS ON HUMAN SPERM AND SEMINAL PLASMA CHARACTERISTICS
}

\author{
S.V. Andreychenko*, A.V. Klepko, L.V. Gorban, O.A. Motryna, L.V. Grubska, O.V. Trofimenko \\ State Institution "National Research Center for Radiation Medicine of the National Academy of Medical \\ Sciences of Ukraine”, Kyiv 04050, Ukraine
}

Aim: The research was aimed on analysis of the remote consequences of Chornobyl accident on the reproductive function of men adult residing in Ukraine. Materials and Methods: 232 male volunteers with mean age of 34 years (range 20-47) from 5 different regions of Ukraine (Zhytomyr, Ivano-Frankivsk, Kyiv, Poltava, and Kyiv city) were enrolled in cross-sectional studies of long term radiation effects on seminal plasma and sperm. All manipulations, analysis and classification of ejaculates were done accordingly to WHO recommendations. The content of neutral $\alpha$-glucosidase, fructose, citric acid in the seminal plasma was determined by spectrophotometry, L-carnitine - by high performance liquid chromatography, zinc - by atomic absorption spectroscopy. Results: In the men residing in the regions heavily contaminated with radioonuclides, the decreased sperm quality with concurrent asthenozoospermia, oligozoospermia, teratozoospermia, asthenoteratozoospermia, oligoasthenoteratozoospermia and oligoteratozoospermia was revealed. Moreover, the concomitant shifts in seminal plasma content of neutral $\alpha$-glucosidase, fructose, citric acid, L-carnitine and zinc were detected. Conclusion: The study has revealed the ample sperm and semen abnormalities amongst the inhabitants of radiation polluted territories that should have to be a subject of careful research in forthcoming years. This article is a part of a Special Issue entitled "The Chornobyl Nuclear Accident: Thirty Years After".

Key Words: human sperm, seminal plasma, radiation pollution, exposure dose, Chornobyl accident.

About 30 years from Chornobyl accident have elapsed. A said period has enriched our knowledge about physicochemical facets of radiation and provided new insight into radiation damage from environmental or occupational radiation exposure on the basis of advanced molecular techniques and gene sequencing. Yet, the high pollution of numerous territories in Ukraine, Belarus and Russian Federation by radionuclides, such as caesium, strontium, plutonium and americium, created unique natural conditions for observing radiation effects on different plant and animal species as well as human beings that resulted from chronic low-dose ionizing irradiation of internal or external origin and their combination, too. Apart from this, a number of people who participated in liquidation of Chornobyl catastrophe were subjected to acute ionizing irradiation or long-term irradiation with relatively low dose rate. In this connection we may regard the experimental data collected in the course of Chornobyl disaster and in its aftermath as an invaluable scientific heritage, which requires further thorough evaluation and analysis in collation with the results of previous investigations undertaken in consequence of atomic bombings in Hiroshima and Nagasaki, accidents on nuclear power plants in former Soviet Union and USA and the radiation exposure caused by Fukushima Daiichi fallout in March 2011.

Genotoxic effects of post-Chornobyl environmental radiation pollution were studied thoroughly on house mice (Mus musculus) by Pomerantseva et al. [1] over 1986-1994. The dose rate of $\gamma$-irradiation on the soil surface where house mice lived ranged from 0.0002 to $2 \mathrm{mGy} / \mathrm{h}$. The frequency of reciprocal

Submitted: September 14, 2016.

*Correspondence: E-mail: sergiian.sa@gmail.com

Abbreviation used: NAG - neutral a-glucosidase translocations in mouse spermatocytes was shown to be relatively low but increased with the dose rate. Embryo mortality was of the highest value in 1987, especially in the area of the elevated radionuclide contamination, where the absorbed dose on animal gonads constituted 3-4 Gy, and then gradually declined in the coming years.

Germ cells in the seminiferous epithelium are frequently regarded to be protected from chemical toxicants and radionuclides by the blood - testis barrier, which is formed by tight junctions between adjacent Sertoli cells at their basolateral surfaces. However, several studies in rodents have provided the arguments in favor of possibility for some actinide radionuclides, namely plutonium, americium and polonium, to bind to serum transferrin and circumvent blood - testis barrier through natural iron-transferrin pathway. Of note, Pu retention half-time in animal testis may attain approximately 1 year. Further, quantitative autoradiography has demonstrated that testicular Pu in mice is not distributed uniformly throughout the testis but localized primarily in the lysosomal compartment of interstitial tissue macrophages and then in the adluminal compartment of the seminiferous tubule [2-4].

Consequently, spermatogonial stem cells should become an open target for a-particle attack thereby accumulating high radiation doses. Further intratubular accumulation of $\mathrm{Pu}$ and other actinide radionuclides may subsequently create additional biological hazards to those resulted from interstitial tissue radionuclide deposits. Due to this, the induction of dominant lethal mutations through ${ }^{238} \mathrm{Pu}$ incorporated into mice was detected [5].

The detailed examination of testicular germ cells in mouse under different radiation dose exposures revealed that incompleteness of spermatogonial stem 
cell post-radiation recovery and DNA repair stipulated a surge of sperm head abnormalities along with increased susceptibility to in situ DNA denaturation at the doses as low as 12-25 rad. A dose of 100 rad was necessary to invoke a surge in the relative number of diploid elongated spermatids with concomitant reduction of both S-phase cells and haploid spermatids [6].

Screening of genomic short-length nucleotide repeats (4-6 bp) undertaken in groups of human adults and their children permanently residing in Mogilev region of Belarus, which is set in the zone of high radiation pollution due to Chornobyl catastrophe established almost a two-fold raise of mini-satellite mutation frequency compared to non-irradiated controls [7, 8]. However, these results were not corroborated in the studies of children born to survivors of atomic bombing in Hiroshima and Nagasaki as well as among children whose fathers as liquidators had taken part in cleanup works at Chornobyl [9-11]. The discrepancy in the above mentioned researches may have appeared because of radiation had affected different classes of spematogonia, specifically stem spermatogonia in the last two trials instead of differentiating spermatogonia in the former one.

In three retrospective studies of Chornobyl emergency workers 5-6, 7-8 and 13-14 years after radiation exposure, respectively, who received radiation doses in the range 0.001-0.33 Gy during the disaster, men were examined as to the sperm quality of their ejaculates [12-14]. Semen analysis revealed slight worsening of sperm morphology up to $20 \%$ compared to unexposed control in the first trial, whereas in the third one the abnormal spermatozoa were more abundant and constituted in average $60 \%$ of sperm quantity in each ejaculate, $80 \%$ of sperm structure anomalies being the tail defects. 328 liquidators were examined in second research. However, no indirect signs of spermatogenesis disruption were noticed by hormone quantitative measurement [12]. Nevertheless, significantly reduced number of morphologically normal spermatozoa in ejaculate was detected. Apart from this, a higher percentage of cases with teratozoospermia, oligozoospermia and asthenozoospermia in liquidators compared to control was discovered [14].

In contrast to the short-term irradiation, the exposure of residents of Bryansk region (Russian Federation) to chronic low-dose irradiation caused the consecutive decline in circulating testosterone concentration, which was frequently accompanied by a rise of follicular stimulating hormone level in blood as a hallmark of spermatogenesis damage in testicles [13].

Ultramorphological sperm analysis of liquidators 10 year afterwards the catastrophe has detected a high frequency of malformation of sperm organelles, significant surge of incomplete genesis nuclei and amorphous head shapes. In addition, teratozoospermia, asthenozoospermia and oligozoospermia were also identified [15, 16]. Semen analysis during the first years after Chornobyl accident revealed oligozoospermia along with azoospermia in $42.4 \%$ and asthenozoospermia/teratozoospermia in 52.6\% of 229 men examined [17]. Liquidators suffering from the third degree of radiation sickness (3.5-5.5 Gy) continued manifesting aspermia and azoospermia over 6 years while the ones with the second degree of acute radiation sickness (2.0-3.5 Gy) showed the recovery of spermatogenesis, normal sperm counts in ejaculates, but frequent incidence of asthenozoospermia and increased number of abnormal spermatogonia [12, 18, 19]. More detailed studies of semen quality and sperm DNA damage among health workers occupationally exposed to ionizing radiation discovered that effective doses in the range 0.05-5.0 mSv caused sperm aneuploidy, DNA fragmentation and hypermethylation in combination with gross raise of morphologic abnormalities, tail defects and significant reduction of sperm progressive motility [20]. Apart from pathologic changes in semen of Chornobyl liquidators, ultrasound examinations of their prostate and seminal vesicles demonstrated a development of specific alterations similar to chronic prostatitis and vesiculitis [21].

As it follows from all aforesaid, the investigations of human semen in post-Chornobyl period were amply focused on the effects of chronic ionizing radiation on spermatozoid morphology and sperm DNA integrity. Meanwhile the important component of semen, notably seminal plasma, was left without due attention, although its role in promoting sperm movements, egg - sperm interactions and eventually fecundation is invaluable.

In this connection studying the remote effects of Chornobyl accident on seminal plasma quantitative characteristics and quality with regard to sperm functionality is challenging and worth to be pursued. Thereby, the present research aimed to analyze long-term radiation effects on each of two semen compartments, i.e. cellular and fluid, as separately as in conjunction to elucidate the peculiarities of their interplay for fertility potential preservation.

\section{MATERIALS AND METHODS}

Sperm donors. Two hundred and thirty two men volunteers with mean age of 34 years (range 20 to 47) from 5 different regions of Ukraine (Zhytomyr, IvanoFrankivsk, Kyiv, Poltava, and Kyiv city) had given their written consent for participation in research that was then approved by the commission on medical ethics of the National Research Center for Radiation Medicine, which validated the complete accordance of the investigations to the ethical and juridical requirements of the Order No. 281 from 01.11.2000 of the Ministry of Public Health of Ukraine.

All individuals were free from genital infections. They were distributed in 4 groups with regard to the radiation pollution of territories in their settlements. Group 1 included inhabitants of area with ${ }^{137} \mathrm{Cs}$ deposition density $185-550 \mathrm{kBq} / \mathrm{m}^{2}$, group $2-100$ $185 \mathrm{kBq} / \mathrm{m}^{2}$, group $3-20-100 \mathrm{kBq} / \mathrm{m}^{2}$, and group $4-2-10 \mathrm{kBq} / \mathrm{m}^{2}$. 
All subjects were thoroughly interviewed concerning their habits and aptitude for smoking, alcohol, anabolic and drug consumption. Moreover, detailed information about the places of residence before and after Chornobyl explosion as well as past and current diseases was inquired and recorded. Overall visual medical examination was also performed.

Semen analysis. Semen samples were obtained by masturbation into a sterile plastic container after at least three days of sexual abstinence. All manipulations, analysis and classification of ejaculates were done accordingly to WHO recommendations [22]. At the start each ejaculate was subjected to preliminary physical examination, semen volume being measured in calibrated conical glass vial, semen consistency visually by eye and $\mathrm{pH}$ - by special paper strips (Micro Essential Labs, USA). Then ejaculate was left to liquefy at $35^{\circ} \mathrm{C}$ for $30-60 \mathrm{~min}$. Sperm viability was assessed by eosin-nigrosin water solution (1:10). Sperm concentration in semen was calculated using Goryaev's counting chamber (depth $0.1 \mathrm{~mm}$, volume $0.9 \mathrm{~mm}^{3}$ ). Concurrently leukocyte concentration was determined through their differentiation by ortotoluidine for peroxidase activity. Sperm motility was analyzed under light microscope at magnification $\times 400$ with regard to 4 categories: A) spermatozoa with rapid linear movements; B) progressively moving moderate and slow spermatozoa; C) non-progressively moving spermatozoa; D) immotile spermatozoa.

Sperm morphology analysis was performed microscopically in semen smears after staining by hematoxylin according to Papanicolau. Spermatozoon was considered normal if no morphological defects were present in any part of its anatomical structure, i.e. head, neck, mitochondrial helix and tail. In addition, sperm head has to be oval with clearly delineated acrosome, the latter being in length $4.0-5.5 \mu \mathrm{m}$ and 2.5-3.3 $\mu \mathrm{m}$ in width. Further, length to width proportion is to be in the range $1.5-1.75$. Sperm motility was assessed in batch of 400 spermatozoa at random selected in 2 fields of viewing, while for sperm morphology only 100 spermatozoa were used.

Each group of sperm donors was subdivided by virtue of spermogram analysis in normozoospermic, asthenozoospermic, oligozoospermic and teratozoospermic subgroups. Thus, asthenozoospermia was assigned to subjects having $A$ spermatozoa less than $25 \%$ and $A+B$ below $50 \%$. Oligozoospermia was incident to persons with sperm concentration in ejaculate below or equal to $20 \mathrm{mln} / \mathrm{ml}$. Teratozoospermia is a semen pathologic state when less than $30 \%$ of normal spermatozoa are present in ejaculate. We have also elucidated the mixed forms of sperm pathology, e.g. oligoasthenoteratozoospermia, oligoasthenozoospermia, oligoteratozoospermia and asthenoteratozoospermia, which simultaneously contributed to several subgroups. Normozoospermia is a characteristic of individuals containing in their ejaculate more than $25 \%$ of $A$ sperm and $A+B$ higher or equal to $50 \%$. Yet, sperm concentration is to surpass
$20 \cdot 10^{6}$ spermatozoa per $\mathrm{ml}$, the total amount of normal spermatozoa in ejaculate being $30 \%$ or more.

Seminal plasma analysis. For biochemical analysis seminal plasma was separated from spermatozoa by centrifugation at $1000 \mathrm{~g}$ for 10 min over $2 \mathrm{~h}$ after semen receipt. Thereafter supernatant was collected, frozen and stored at $-70{ }^{\circ} \mathrm{C}$ until further processing. Neutral a-glucosidase (NAG) was determined in the hydrolysis reaction of 4-nitrophenyl a-D-glucopyranoside into 4-nitrophenol and a-D-glucopyranoside, 4-nitrophenol being identified spectrophotometrically. The acid isoenzyme was inhibited by addition of $1 \%$ sodium dodecyl sulfate at $\mathrm{pH} 6.8$, so that only the neutral isoform of a-glucosidase was measured [23]. Fructose was identified by technique [24] using $0.1 \%$ resorcine in ethanol. The intensity of resultant bright-red color was registered at $490 \mathrm{~nm}$ against blank containing no fructose by spectrophotometer Specol-211 (Germany). True corrected fructose was calculated as a product [lg $(A+B)$ sperm concentration] $\times$ [fructose]. Zinc concentration in seminal plasma was assessed by atomic absorption spectroscopy on the device Analytik Jena Contr AA 300 (Germany) using its annexed software [25]. L-carnitine determination was done by high performance liquid chromatography on Agilent 1200 (USA) installed with UV-spectrophotometric detector according to protocol [26]. If shortly, free L-carnitine was converted to $\mathrm{p}$-bromphenobromid (pbb)-carnitine ether having absorbance peak at $260 \mathrm{~nm}$. Chromatographic resolution and separation of pbb-carnitine ether was achieved by Lichrospher column $(200 \cdot 4.6 \mathrm{~mm})$ filled in with $\mathrm{SiO}_{2}$ particles of $5 \mu \mathrm{m}$ in diameter. L-carnitine concentration was expressed in $\mu \mathrm{mol} / \mathrm{l}$. Citric acid was determined by ultraviolet method in which the sample is incubated with lactate dehydrogenase and NADH in triethanolamine buffer $(0.1 \mathrm{M}, \mathrm{pH} 7.6$, containing $0.2 \mathrm{mM} \mathrm{ZnCl}_{2}$ ), a shift in absorbance at $340 \mathrm{~nm}$ being noted after addition of citrate lyase [27].

Dosimetric analysis. Assessment of the whole body irradiation doses was carried out according to [28] on the basis of normalized doses of the whole body irradiation according to the following formulae:

$$
N D(\Delta t)=E_{R}{ }^{-1} C_{1} C_{2} P_{\gamma}(\Delta t),
$$

where $N D(\Delta t)$ - normalized equivalent dose of whole body irradiation accumulated over the time $\Delta t$ in the area with radioactive density of ${ }^{137} \mathrm{Cs}$ contamination equal to $37 \mathrm{kBq} / \mathrm{m}^{2}$ at the end of April 1986; $E_{R}$ - the contribution factor of external radiation in the total dose; $\mathrm{C}_{1}-$ the conversion factor for converting exposition dose in tissue absorbed dose; $\mathrm{C}_{2}-$ the conversion factor for converting tissue absorbed dose in equivalent dose; $P_{y}(\Delta t)$ - the exposition dose in free air at the height 1 meter above the ground over the time $\Delta \mathrm{t}$.

$$
\begin{gathered}
I D_{(T)}=\sum_{i=1}^{n} A^{o i} F_{1 i}\left[F_{2 i}+\left(1-F_{2 i}\right) F_{3 i}\right] N D(\Delta t) / 37 \\
T=\sum_{i=1}^{n} \Delta t_{i},
\end{gathered}
$$

where $I D_{(T)}$ - individual equivalent dose accumulated over time $\mathrm{T} ; \mathrm{A}_{o i}-{ }^{137} \mathrm{C}$ s radioactive contamination 
density $\left(\mathrm{kBq} / \mathrm{m}^{2}\right)$ in $i$ - place of residence; $n$ - number of residence places changed by a subject in the period after Chornobyl catastrophe; $F_{1 i}$ - the correction coefficient taking into account a type of a soil in the $i$-place of residence; $F_{2 i}$ - the outdoor occupancy factor in the $i$-place of residence; $N D\left(\Delta t_{i}\right)-$ normalized dose accumulated in the period of time $\Delta t_{i} ; T$ time span from Chornobyl catastrophe or later date (for those who were born after the accident) until the date of sperm examination; $\Delta t_{i}$ - period of time spent in $i$-place of residence.

Data about radioactive pollution of territories in Ukraine were retrieved from Internet resources [29] and special documents devoted to dosimetry of radiation polluted territories [30].

Statistical analysis. Comparison of data for different groups of donors was made using analysis of variances (Anova) and unpaired Student's $t$-test with amendment of Bonferroni. Confidence intervals for mean values were identified using $t$-statistic at $p=0.95$ and standard errors. All statistical tests were two sided and $p<0.05$ was considered statistically significant [31].

\section{RESULTS AND DISCUSSION}

In the research the inhabitants of Zhytomyr, Kyiv, Ivano-Frankivsk, Poltava regions and Kyiv city were enrolled. According to the data from radiodosimetric documents radiation contamination by ${ }^{137} \mathrm{Cs}$ of former two regions changes in the range $20-1480 \mathrm{kBq} / \mathrm{m}^{2}$, in Ivano-Frankivsk and Poltava region it ranges 20 $100 \mathrm{kBq} / \mathrm{m}^{2}$ and $2-10 \mathrm{kBq} / \mathrm{m}^{2}$, respectively. Moreover, Zhytomyr and Kyiv regions in contrast to IvanoFrankivsk and Poltava regions are polluted albeit partly by radioinuclides of plutonium $\left({ }^{238-242} \mathrm{Pu}\right)$, americium $\left({ }^{241} \mathrm{Am}\right)$, and strontium $\left({ }^{90} \mathrm{Sr}\right)$. Taking these facts into account we made up four groups of men volunteers. Thus, group 1 comprised men from Zhytomyr region, group 2 - from Kyiv city and Kyiv region, group $3-$ from Ivano-Frankivsk region, and group 4 - from Poltava region who had been living on urban or rural territories with relevant ${ }^{137} \mathrm{Cs}$ deposition densities. The data concerning group characteristics, individual equivalent dose means and age means are provided in Table 1. It is worth mentioning for the investigations only healthy sperm donors were admitted while those abusing smoking and alcohol, using anabolics and antibiotics protractedly as well as having suffered from different testicular pathologies, e.g. orhitis, varicocele, cryptorhidism and so forth, were excluded.

Table 1. Comparative analysis of individual characteristics of men who participated in the epidemiological studies of sperm quality for human male population of Ukraine in the post-Chornobyl remote period

\begin{tabular}{ccccc}
\hline Group & $\begin{array}{c}\text { Territorial radia- } \\
\text { tion contamination } \\
\text { by }{ }^{137} \mathrm{Cs}, \mathrm{kBq} / \mathrm{m}^{2}\end{array}$ & $\begin{array}{c}\text { Total number } \\
\text { of volunteers (ur- } \\
\text { ban/rural residents) }\end{array}$ & $\begin{array}{c}\text { Individual } \\
\text { age mean, } \\
\text { years }\end{array}$ & $\begin{array}{c}\text { Individual } \\
\text { equivalent dose } \\
\text { mean, mSv }\end{array}$ \\
\hline 1 & $185-550$ & $60(45 / 15)$ & $33.3 \pm 0.7$ & $18.08 \pm 0.39$ \\
2 & $100-185$ & $41(32 / 9)$ & $31.7 \pm 0.8$ & $7.98 \pm 0.24$ \\
3 & $20-100$ & $52(28 / 24)$ & $32.9 \pm 0.5$ & $3.78 \pm 0.12$ \\
4 & $2-10$ & $32(24 / 8)$ & $32.3 \pm 0.4$ & $0.28 \pm 0.04$ \\
\hline
\end{tabular}

No statistically valid differences in age means between groups were found, whereas a group individual equivalent dose mean showed a tendency for sequential increase in the range $0.28-18.0 \mathrm{mSv}$ starting from group 4 towards group 1 parallel to ${ }^{137} \mathrm{Cs}$ deposition density elevation in the settlement. Analysis of sperm qualities (Table 2) has elucidated the prevalence of progressively moving spermatozoa with high kinetic performance and normal values of sperm concentration in ejaculate for group 4, while in group 3 the sperm concentration decreased by $41 \%$. Concurrently the amount of immotile spermatozoa grew up threefold while sperm abnormalities increased fourfold. The further worsening of sperm characteristics was also incident to groups 2 and 1 , the latter showing the utmost mean value of sperm abnormalities and immotility in combination with obvious slowing of spermatozoid spatial dislocations. Almost 2.7-fold drop of mean sperm concentration in group 1 relative to group 4 was revealed.

Table 2. Analysis of physiological properties of sperm collected from donors inhabiting territories with different ${ }^{137} \mathrm{Cs}$ deposition densities

\begin{tabular}{|c|c|c|c|c|}
\hline \multirow{2}{*}{ Parameters } & \multicolumn{4}{|c|}{ Mean value ( \pm SE) } \\
\hline & Group & Group 2 & Group 3 & Group 4 \\
\hline $\begin{array}{l}\text { oerm concentration } \times 10^{6} \text { sper- } \\
\text { atozoa } / \mathrm{ml}\end{array}$ & & & $58 \pm 17$ & \\
\hline rapid progressive mo- & $15 \pm 6^{a}$ & $20 \pm 7^{b}$ & $28 \pm 9$ & $39 \pm 13^{\text {ab }}$ \\
\hline and low & $24 \pm 8^{a}$ & $35 \pm 11$ & $29 \pm 10$ & $44 \pm 11^{a}$ \\
\hline gressive motili- & $17 \pm 6^{\mathrm{a}}$ & $13 \pm 6$ & $11 \pm 7$ & $6 \pm 2^{\mathrm{a}}$ \\
\hline $\begin{array}{l}\text { nmotile sperm } \\
\text { bnormal sper }\end{array}$ & $\begin{array}{l}44 \pm 15^{\mathrm{a}} \\
58 \pm 15^{\mathrm{a}}\end{array}$ & $\begin{array}{l}32 \pm 7^{\mathrm{b}} \\
42 \pm 11^{\mathrm{b}}\end{array}$ & $\begin{array}{l}32 \pm 10^{c} \\
21 \pm 9^{c}\end{array}$ & $\begin{array}{c}11 \pm 5^{\mathrm{abc}} \\
7 \pm 2^{\mathrm{abc}}\end{array}$ \\
\hline
\end{tabular}

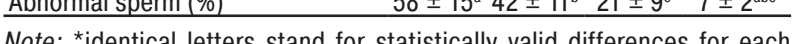
of 6 mentioned sperm parameters between the groups $(p<0.05)$ : a - groups 1 and $4 ; b$ - groups 2 and $4 ; c-$ groups 3 and 4 .

The aggravation of sperm velocity, motility, concentration and morphology in strict dependence on the level of territorial radiation contamination showed up in appearing of a number of semen pathologic states in group 1 where normozoospermia together with asthenozoospermia, oligozoospermia, teratozoospermia, asthenoteratozoospermia, oligoasthenoteratozoospermia and oligoteratozoospermia were detected. In contrast to this, in group 4 normozoospermia prevailed (Table 3).

Table 3. Numerical diversity of semen pathology emerging amongst men from regions with different radiation pollution of territories

\begin{tabular}{lcccc}
\hline \multirow{2}{*}{ Semen status } & \multicolumn{4}{c}{ Number of persons } \\
\cline { 2 - 5 } & Group 1 & Group 2 & Group 3 & Group 4 \\
\hline Normozoospermia & 13 & 17 & 18 & 28 \\
Asthenozoospermia & 12 & 5 & 10 & 1 \\
Oligozoospermia & 7 & 3 & 7 & 2 \\
Teratozoospermia & 11 & 6 & 6 & 0 \\
Asthenoteratozoospermia & 13 & 7 & 5 & 0 \\
Oligoasthenoteratozoospermia & 1 & 2 & 3 & 0 \\
Oligoasthenozoospermia & 1 & 0 & 2 & 1 \\
Oligoteratozoospermia & 2 & 1 & 1 & 0 \\
\hline
\end{tabular}

At the chart (Fig. 1) the incidence distribution of semen pathologic states in each group is presented. Noteworthy, teratozoospermia was incident to groups 1, 2 and to lesser extent to group 3. By contrast, asthenozoospermia and oligozoospermia were present in all 4 groups, the latter state being less frequent in its manifestation.

Admittedly NAG is a specific marker of epididymices. Its contents in seminal plasma of patients with obstruc- 
tive and testicular azoospermia decreases notably [32]. In our research the enzymatic activity of NAG was shown to be of maximal mean value for the men of group 4, whereas in the group 1 it fell 1.4 fold. Yet, NAG diminution proceeded stepwise and proportionally to individual equivalent dose mean elevation (Table 4, Fig. 2, a). Supposedly, rapid NAG decline on the highly radiation contaminated territories $\left(185-550 \mathrm{kBq} / \mathrm{m}^{2}\right)$ may have originated, from the one hand, as a result of germ cell radiation damage and subsequent germinal aplasia development due to $\mathrm{Pu}$ and $\mathrm{Am}$ radionuclides accumulation in testes, notably in seminiferous tubule adluminal compartment [2-4]. On the other hand, the external irradiation must have caused both the direct impairment of germ line in testis and the depravation of hormonal regulation in hypothalamus-pituitarygonad axis. These ideas are in line with evident rise of sperm abnormality associated with quite pronounced spermatozoid immobility in inhabitants of highly radiation polluted areas (see Table 2).

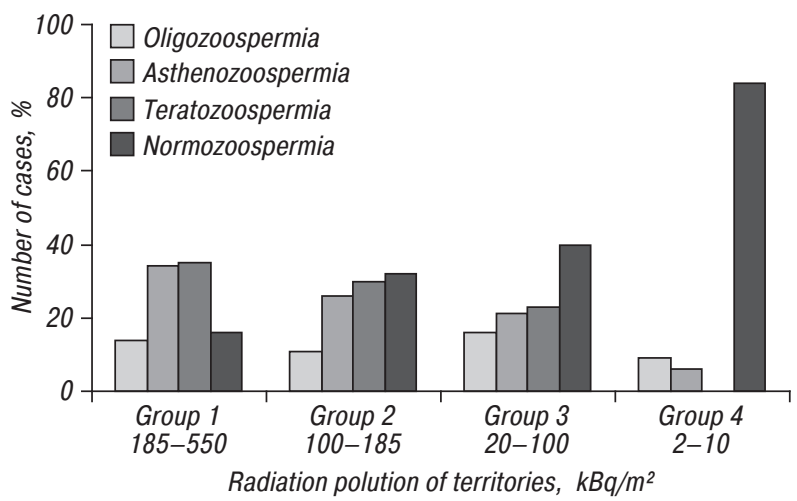

Fig. 1. Incidence of different sperm pathologies among men inhabiting radiation polluted territories of Ukraine
Table 4. Impact of post-Chornobyl radiation on biochemical characteristics of seminal plasma from human males inhabiting radiation polluted territories of Ukraine

\begin{tabular}{lcccc}
\hline Semen biochemical & \multicolumn{4}{c}{ Group } \\
\cline { 2 - 5 } \multicolumn{1}{c}{ parameters } & 1 & 2 & 3 & 4 \\
\hline NAG, $\mathrm{mlU} / \mathrm{ml}$ & $11.4 \pm 0.3^{\text {abc }}$ & $21.5 \pm 0.5^{\text {bde }}$ & $22.7 \pm 0.6^{\text {cef }}$ & $24.3 \pm 0.8^{\text {adf }}$ \\
L-carnitine, $\mu \mathrm{mol} / \mathrm{l}$ & $203.4 \pm 6.8^{\text {abc }}$ & $259.9 \pm 7.1^{\text {ded }}$ & $325.8 \pm 8.2^{\text {cef }}$ & $348.9 \pm 9.6^{\text {adf }}$ \\
Fructose, $\mathrm{mmol} / \mathrm{l}$ & $9.6 \pm 0.5^{\text {abc }}$ & $11.4 \pm 0.6^{\text {bde }}$ & $14.9 \pm 0.7^{\text {ce }}$ & $14.8 \pm 0.6^{\text {ad }}$ \\
True corrected semi- & $13.1 \pm 0.4^{\text {abc }}$ & $20.5 \pm 0.7^{\text {bde }}$ & $27.5 \pm 1.1^{\text {ce }}$ & $29.1 \pm 1.2^{\text {ad }}$ \\
nal fructose, $\mathrm{mg} / \mathrm{ml}$ & & & & \\
Citric acid, $\mathrm{mmol} / \mathrm{l}$ & $21.3 \pm 0.1^{\text {abc }}$ & $26.2 \pm 0.3^{\text {bde }}$ & $28.4 \pm 0.2^{\text {cef }}$ & $30.3 \pm 0.4^{\text {adf }}$ \\
Zinc, $\mathrm{mg} / \mathrm{dl}$ & $12.6 \pm 0.6^{\text {abc }}$ & $14.0 \pm 0.7^{\text {dd }}$ & $14.2 \pm 0.7^{\text {cf }}$ & $17.1 \pm 0.9^{\text {adf }}$ \\
\hline
\end{tabular}

Note: *identical letters stand for statistically valid differences for each of 6 mentioned biochemical parameters between the groups $(p<0.05)$ : a groups 1 and $4 ; b$ - groups 1 and $2 ; c-$ groups 1 and $3 ; d-$ groups 2 and 4 ; e-groups 2 and $3 ; f-$ groups 3 and 4 .

L-carnitine is the next informative epididymal biomarker. It was shown to be taken up from bloodstream by epididymal epithelium and then transferred to epididymal lumen, being concentrated 100 fold therein. L-carnitine is a zwitterionic compound of beta-hydroxy-gamma-N-trimethylaminobutyric acid. It is synthesized mainly by hepatocytes in liver and partly by kidney. The principal physiological role of carnitine deals with fatty acid transport to mitochondrial matrix and excessive mitochondrial acetyl-coenzyme A preservation in the form of L-acetyl-carnitine [33]. In group 4 mean value of $L$-carnitine concentration in seminal plasma was maximal, while in group 3 it slightly decreased. Thereafter it dropped abruptly in group 2 and then attained minimal level in group 1, which differed from group 4 just about 1.7 fold.

The dose dependence of L-carnitine group mean concentration changes in seminal plasma is plotted on Fig. 2, $b$. The graph bending after the dose $3.78 \mathrm{mSv}$ may be accounted for by the additional radiation damage of epididymices in groups 1 and 2 by virtue of ac-
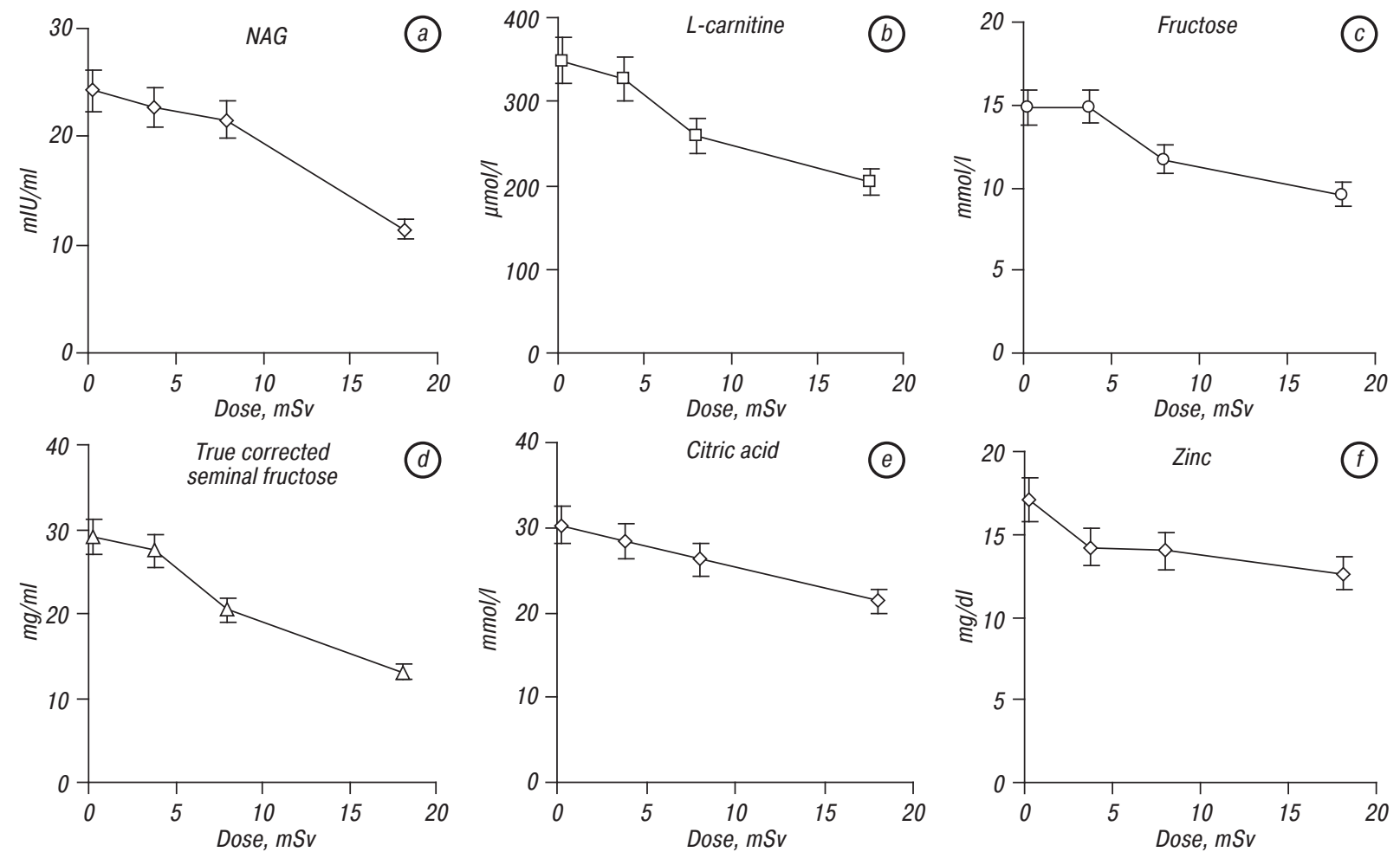

Fig. 2. Impact of accumulated individual dose on the enzymatic activity of NAG (a) and quantitative characteristics of L-carnitine (b), fructose $(c)$, true corrected seminal fructose $(d)$, citric acid $(e)$ and zinc $(f)$ in seminal plasma of sperm donors from groups 1-4 
tinide radionuclides migrating along seminiferous tubules primarily to rete of testicle and then to epididymis and farther. Thereof the radiation lesion of epididymal epithelium is quite conceivable. Incidentally, downregulation of carnitine active transfer from blood stream to epididymal lumen could have concurred, thereby dissipating carnitine concentration gradient therein.

Fructose is a biomarker of seminal vesicles, which are known to supply a great deal of seminal plasma to semen [34]. Fructose provides spermatozoa with catabolic substrates for further energy generation and moving. The gradual increase in fructose concentration in seminal plasma was observed when advancing from group 1 to group 3 . However, no differences were noticed for said parameter between group 3 and 4 . Conversely, the true corrected seminal fructose sequentially elevated from group 1 to group 4 (see Table 4 and Fig. 2, $c, d$ ) and showed dose dependence close to linear for the whole dose span studied.

Attenuation of fructose secretion by seminal vesicles was indicative of this accessory gland hypofunction development. The latter could have arisen because of blood testosterone diminution under chronic irradiation [13]. Moreover, radionuclide deposition in skull bones in close vicinity to hypophysis would stimulate gonadotropin secretion that is favored by the results of longitudinal examination of women living in areas along the Techa River (Russian Federation) contaminated by nuclear accidents/waste from the nuclear facility over 1950-1997 who showed multiple pregnancies and delivery in consequence to incorporation of ${ }^{90} \mathrm{Sr}$ in the sella turcica [35]. Meanwhile gonadotropin elevation in conjunction with germinal aplasia progressing by far triggers testosterone conversion into estrogen [36].

Further analysis of zinc content in semen fluid has provided additional support to above mentioned arguments. Thus, zinc along with citric acid is supplied to seminal plasma by prostate gland, which accumulates zinc in glandular cells through special ion-transporter. Yet, the latter is known to be under the direct testosterone regulation [36, 37]. In normal physiologic conditions zinc elevation causes inhibition of citrate aconitase and obstruction of citrate conversion into isocitrate. Consequently, zinc accumulation in prostate glandular epithelium is accompanied by further citrate concentration growth therein and vice versa. This aftermath the citric acid contents increased consecutively from group 1 to group 4 that was followed by concomitant surge of zinc concentration in seminal plasma (see Table 3). Incidentally dose dependent curves showed almost linear abatement up to $3.75 \mathrm{mSv}$ and then abrupt fall at $18 \mathrm{mSv}$ for both zinc and citrate (Fig. 2, e,f). Noteworthy, lowering of citrate concentration may be indicative of prostate carcinoma increased risk development [38]. Moreover, worsening of sperm quality is also incident to men prone to testicular cancer [39]. In this connection, radiation pollution of territories in Ukraine by radionuclides was shown to be a potent stimulator of prostate tumorigenesis [40].
Thereby, the studies performed have revealed the ample sperm and semen abnormalities amongst the inhabitants of radiation polluted territories that should have to be a subject of careful research in forthcoming years in order to prevent the expansion of demographic crisis and cancer spreading in male population of Ukraine.

\section{REFERENCES}

1. Pomerantseva MD, Ramaiya LK, Chekhovich AV. Genetic disorders in house mouse germ cells after the Chernobyl catastrophe. Mutat Res 1997; 381: 97-103.

2. Hoyes KP, Morris ID. Environmental radiation and male reproduction. Int J Androl 1996; 19: 199-204.

3. Preist ND, Jackson S. The uptake and redistribution of ${ }^{241} \mathrm{Pu}$ within the gonads. Int J Radiat Biol Relat Stud Phys Chem Med 1978; 34: 49-65.

4. Hoyes KP, Morris ID, Hendry JH, Sharma HL. Transferrin mediated uptake of radionuclides by the testis. J Nucl Med 1996; 37: 336-40.

5. Pomerantseva MD, Ramaya LK, Shevchenko VA, et al. Evaluation of the genetic effects of ${ }^{238} \mathrm{Pu}$ incorporated into mice. Mutat Res 1989; 226: 93-8.

6. Sailer BL, Jost LK, Erickson KR, et al. Effects of X-irradiation on mouse testicular cells and sperm chromatin structure. Environ Mol Mutagen 1995; 25: 23-30.

7. Dubrova YE, Nesterov VN, Krouchinsky NG, et al. Human minisatellite mutation rate after the Chernobyl accident. Nature 1996; 380: 683-6.

8. Dubrova YE, Nesterov VN, Krouchinsky NG, et al. Further evidence for elevated human minisatellite mutation rate in Belarus eight years after the Chernobyl accident. Mutat Res 1997; 381: 267-78.

9. Kodaira M, Satoh C, Hiyama K, Toyama K. Lack of effects of atomic bomb radiation on genetic instability of tandem-repetitive elements in human germ cells. Am J Hum Genet 1995; 57: 1275-83.

10. Furistu K, Ryo H, Yeliseeva KG, et al. Microsatellite mutations show no increases in the children of the Chernobyl liquidators. Mutat Res 2005; 581: 69-82.

11. Livshits LA, Malyarchuk SG, Luk'yanova EM, et al. Heritable mutations at some minisatellite loci analysis in children of liquidators of Chernobyl accident consequences. Int J Radiat Med 1999; 1: 101-6.

12. Birioukov A, Meurer M, Peter RU, et al. Male reproductive system in patients exposed to ionizing irradiation in the Chernobyl accident. Arch Androl 1993; 30: 99-104.

13. Goncharov NP, Katsiya GV, Kolesnikova GS, et al. Endocrine and reproductive health status of men who had experienced short-term radiation exposure at Chernobyl. Int J Androl 1998; 21: 271-6.

14. Tsyb AF, Kaplan MA, Lepekhin NP. Assessing the reproductive function in the Chernobyl emergency workers 13-14 years after the radiation disaster. Radiat Risk 2002; (13): 42-4 (in Russian).

15. Fischbein A, Zabludovsky N, Eltes F, et al. Ultramorphological sperm characteristics in the risk assessment of health effects after radiation exposure among salvage workers in Chernobyl. Environ Health Perspect 1997; 105 (Suppl 6): 1445-9.

16. Bartoov B, Zabludovsky N, Eltes F, et al. Semen quality of workers exposed to ionizing radiation in decontamination work after the Chernobyl nuclear reactor accident. Int J Occup Environ Health 1997; 3: 198-203.

17. Gorpinchenko II, Boyko NI. Semen parameters of clean-up workers of Chernobyl accident. Int J Androl 1997; 20 (Suppl 1): 63. 
18. Cheburakov YuYu, Cheburakova OP. Disorders of spermatogenesis in people working at the clean-up of the Chernobyl nuclear power plant accident. Radiats Biol Radioecol 1993; 33: 771-4 (in Russian).

19. Yablokov AV, Nesterenko VB, Nesterenko AV. Chernobyl. Consequences of the Catastrophe for People and the Environment. Boston: Blackwell Publ, 2009. 400 p.

20. Kumar D, Salian SR, Kalthur G, et al. Semen abnormalities, sperm DNA damage and global hypermethylation in health workers occupationally exposed to ionizing radiation. PLoS ONE 2013; 8: e69927.

21. Evdokimov VV, Erasova VI, Demin AI, et al. State of the reproductive system of men who participated in the cleaning-up of aftereffects of the Chernobyl AES accident. Med Tr Prom Ekol 1993; (3-4): 25-6 (in Russian).

22. World Health Organization. WHO Laboratory Manual for the Examination of Human Semen and Sperm-Cervical Mucus Interaction, $4^{\text {th }}$ ed. Cambridge: Cambridge Press, 1999. 188 p.

23. Cooper TG, Yeung $\mathrm{CH}$, Nashan $\mathrm{D}$, et al. Improvement in the assessment of human epididymal function by the use of inhibitors in the assay of alpha-glucosidase in seminal plasma. Int J Androl 1990; 13: 297-305.

24. Gonzales GF, Villena A. True corrected seminal fructose level: a better marker of the function of seminal vesicles in infertile men. Int J Androl 2001; 24: 255-60.

25. Kondratova YuA, Klepko AV, Andreychenko SV. Comparative analysis of semen quality along with L-carnitine, fructose, zinc and ascorbate contents in seminal plasma of men from different regions of Ukraine. Physics of the Alive 2010; 18: 70-4 (in Ukrainian).

26. Li K, Li W, Huang Y. Determination of free L-carnitine in human seminal plasma by high performance liquid chromatography with pre-column ultraviolet derivatization and its clinical application in male infertility. Clin Chim Acta 2007; 378: $159-63$

27. Kavanagh JP, Darby C. The interrelationships between acid phosphatase, aminopeptidase, diamine oxidase, citric acid, $\beta$-glucuronidase, $\mathrm{pH}$ and zinc in human prostatic fluid. Int J Androl 1982; 5: 503-12.

28. Malko MV. Doses of the whole body irradiation in Belarus as a result of the Chernobyl accident. In: Many-sided Approach to the Realities of the Chernobyl NPP Accident.
Summary of the Consequences of the Accident Twenty Year After (II). Imanaka T, ed. Kyoto University, Japan: KURRIKR-139, 2008; 136-46.

29. Chernobyl, Pripyat, Chernobyl nuclear power plant, and Chernobyl exclusion zone [homepage on the Internet]. Available from: http://www.ncru.inf.ua/publications/index.htm.

30. Collection of dosimetric passports issued to the inhabited settlements which had been subjected to radioactive contamination in Chornobyl accident aftermath. Compendium No 1. Kyiv: Polimed, 1991. 86 p. (in Russian).

31. Bland M. An Introduction to Medical Statistics, $3^{\text {rd }}$ ed. New York: Oxford Univ Press Inc, 2000. 410 p

32. Zöpfgen A, Priem F, Sudhoff F, et al. Relationship between semen quality and the seminal plasma components carnitine, alpha-glucosidase, fructose, citrate and granulocyte elastase in infertile men compared with a normal population. Hum Reprod 2000; 15: 840-5.

33. Ahmed SD, Karira KA, Jagdesh, Ahsan S. Role of L-carnitine in male infertility. J Pak Med Assoc 2011; 61: 732-6.

34. Wetterauer U. Recommended biochemical parameters for routine semen analysis. Urol Res 1986; 14: 241-6.

35. Shalaginov SA, Akleev AV. Multiple delivery in women affected by chronic radiation in Techa river catchment settlements. Med Radiol Radiat Safety 2010; 55 (3): 29-36 (in Russian).

36. Andrology. Male Reproductive Health and Dysfunction, $3^{\text {rd }}$ ed. Neischlag E, Behre HM, Neischlag S, eds. Springer-Verlag Berlin Heidelberg, 2010. 629 p.

37. Abdella AM, Omer Al-F, Al-Aabed BH. Biochemical markers in semen and their correlation with fertility hormones and semen quality among Sudanese infertile patients. Afr J Biochem Res 2010; 4: 255-60.

38. Clarke RA, Schirra HJ, Catto JW, et al. Markers for detection of prostate cancer. Cancers (Basel) 2010; 2: 1125-54.

39. Sharpe RM. Lifestyle and environmental contribution to male infertility. Br Med Bull 2000; 56: 630-42.

40. Vosianov AF, Romanenko AM, Zabarko LB, et al. Prostatic intraepithelial neoplasia and apoptosis in benign prostatic hyperplasia before and after the Chernobyl accident in Ukraine. Pathol Oncol Res 1999; 5: 28-31. 